\title{
La "Aluminosis" del cemento aluminoso o un término nuevo para una clásica enfermedad
}

RAFAEL TALERO MORALES, Dr. en Quimica Industria FERNANDO TRIVIÑO VÁZQUEZ, Dr. en Ciencias Quimicas JORGE PALACIOS DE MARÍA, Arquitecto FRANCISCO FELIX DIAZ GARCIA, Ldo. en Ciencias Químicas ICCET/CSIC/ESPAÑA Serrano Galvache, s/n. 28033 MADRID/España

\section{RESUMEN}

La reciente noticia aparecida en medios de comunicación social, principalmente en las Islas Canarias*, sobre el gran deterioro que se detecta en el hormigón de cemento aluminoso, al sufrir una enfermedad degenerativa denominada ALUMINOSIS, nos ha llevado - precisamente por el término ALUMINOSIS - a matizar y precisar las caracteristicas y particularidades de esa aparente nueva enfermedad del cemento aluminoso, permitiéndonos demostrar que dicha enfermedad no es nueva pese a su posible originalidad fonética.

En este artículo se describe la composición mineralógica, fabricación y utilización de los cementos aluminosos, as como las 3 enfermedades que más les son propias y les pueden afectar y sus consecuencias adicionales, especificando dentro de qué enfermedades de entre las tres se puede encuadrar la ALUMINOSIS y el motivo de su origen. Finalmente se dan unas Normas de Buena Práctica y unas Prescripciones y Proscripciones para su utilización, terminando con la exposición de un caso real de edificación deteriorada gravemente y que fue ejecutada con hormigón de cemento aluminoso.

\section{$S U M M A R Y$}

The recent item of news that appeared mainly in news papers, journals, etc.; of the Canary Islands, in relation to the great deterioration which is detected in the concrete of aluminous cement. This is degenerative disease which is called ALUMINOSIS. This has taken us - precisely on account of the term ALUMINOSIS- to tinge and to precise the characteristcs and particularities of that so-called new desease of the aluminous cement, allowing us to demostrate that the desease ALUMINOSIS is not new in spite of its possible phonetic originality.

This paper describes the mineralogical composition, the manufacturing and use of the aluminous cements and also its three more common deseases which can affect it and their additional consequences, specifying in which three deseases can we place the ALUMINOSIS and its origin. Finally this paper gives a Code of "Good Practice" and some Prescriptions and Proscriptions to be used the aluminous cement, ending this paper with the description of real case of a building very deteriorated because of ALUMINOSIS. These building was made with concrete of aluminous cement.

\section{EL CEMENTO ALUMINOSO: SU COM- POSICION, FABRICACION Y TEXTURA}

Se ha dicho muchas veces que los cementos son "algo vivo". Esta designación es algo más que la expresión gráfica de una sucesión de reacciones que nacen en una mezcla de agua y cemento, y que finalizan en un lejano estado termodinámicamente estable. Entre uno y otro momento, es decir, durante su evolución, pueden aparecer fases del proceso con características mecánico-resistentes menores de las previstas por diversas causas ajenas, o no, al propio cemento, como puede ser el caso del cemento aluminoso y no para el cemento portlad, en el que las causas propiamente intrínsecas que afectan a su durabilidad, en me-

\footnotetext{
* A consecuencia del ciclo de conferencias llevado a cabo por el primer autor de este artículo, bajo el título "INFLUENCIA DE LOS DIFERENTES TIPOS DE CEMENTOS, PUZOLANAS $Y$ OTROS COMPONENTES DEL HORMIGÓN EN SU DURABILIDAD", en Las Palmas de Gran Canaria y Tenerife.
}

dios naturales no agresivos, son prácticamente nulas. De aquí que suele decirse con fundamento de los hormigones de cemento portland, que son prácticamente eternos en las condiciones naturales de servicio no agresivas para los mismos.

Así pues sobre el cemento aluminoso y la durabilidad de los hormigones, con éste preparados, podemos decir que el cemento aluminoso -cuya invención se atribuye a J. Bried, y además recibe diferentes denominaciones, tales como: "Cemento de Bauxita", "Cemento Fundido", "Cemento de Alúmina", etc.- es un conglomerante hidraúlico formado por una mezcla intima de piedra caliza y bauxita pulverizadas adecuadamente, cuya mezcla es calcinada hasta su fusión (en horno eléctrico) o sinterización (en horno giratorio) y molienda conforme a las normas.

El color de este cemento es en general marrón, pero el cemento Lafarge es casi negro, habiendo también algunos tipos blanquecinos. 
La diferencia entre el cemento aluminoso y el portland estriba, en primer lugar, en sus composiciones química y mineralógica.

La Tabla I recoge estas diferencias, las máximas de las cuales residen en el contenido de alúmina $\mathrm{Al}_{2} \mathrm{O}_{3}(\%)$-lo que se refleja también en los módulos silícico y de fundentes- seguido del contenido de cal, $\mathrm{CaO}$ (\%). Ambas diferencias serán, como veremos, determinantes en ocasiones $y$, entre otros motivos, por la escasa durabilidad de sus hormigones comparada con la de los de cemento portland.

La característica fundamental del cemento aluminoso fundido es que, gracias a su endurecimiento rápido, sus hormigones presentan al cabo de 6 horas una resistencia mecánica del mismo orden de magnitud que la obtenida al cabo de 28 días con hormigones de cemento portland análogos, y que la obtenida al cabo de 7 días con hormigones de supercemento. Ello permite, entre otras cosas, que el ritmo de construcción de diversas obras civiles, edificación, etc., se pueda acelerar notablemente, además de los beneficios económicos directos o indirectos que de ello puedan derivar.

El fraguado y endurecimiento del cemento aluminoso, tras su hidratación, son muy exotérmicos y muchísimo más que el cemento portland. $Y$ esta particularidad hace necesarias algunas precauciones cuando se ponen en obra importantes masas de hormigón. En compensación, este desprendimiento rápido de calor permite el endurecimiento normal de los hormigones de cemento aluminoso a bajas temperaturas.

El endurecimiento se efectúa originándose $\mathrm{CAH}_{10}$ sin liberación de hidróxido de calcio, $\mathrm{Ca}(\mathrm{OH})_{2}$, según la reacción siguiente:

$$
\mathrm{CA}+10 \mathrm{H}_{2} \mathrm{O} \rightarrow \mathrm{CAH}_{10}
$$

$Y$ dado el elevado volumen molecular $\mathrm{Vm}$ de dicho hidrato y su lógica abundancia, así como también de las restantes fases hexagonales posibles, que también se puedan formar y que se exponen al inicio del apartado II, ello podría quizás, permitir, además de todo lo anterior;

- una mayor colmatación de los poros del hormigón resultante en comparación con la del cemento portland, $y$

- justificar los mayores valores de resistencias mecánicas a edades iniciales, especialmente alcanzados por los morteros $y$ hormigones de cemento aluminoso sobre los correspondientes de cemento portland.

TABLA I

Composición química del cemento portland y del cemento aluminoso

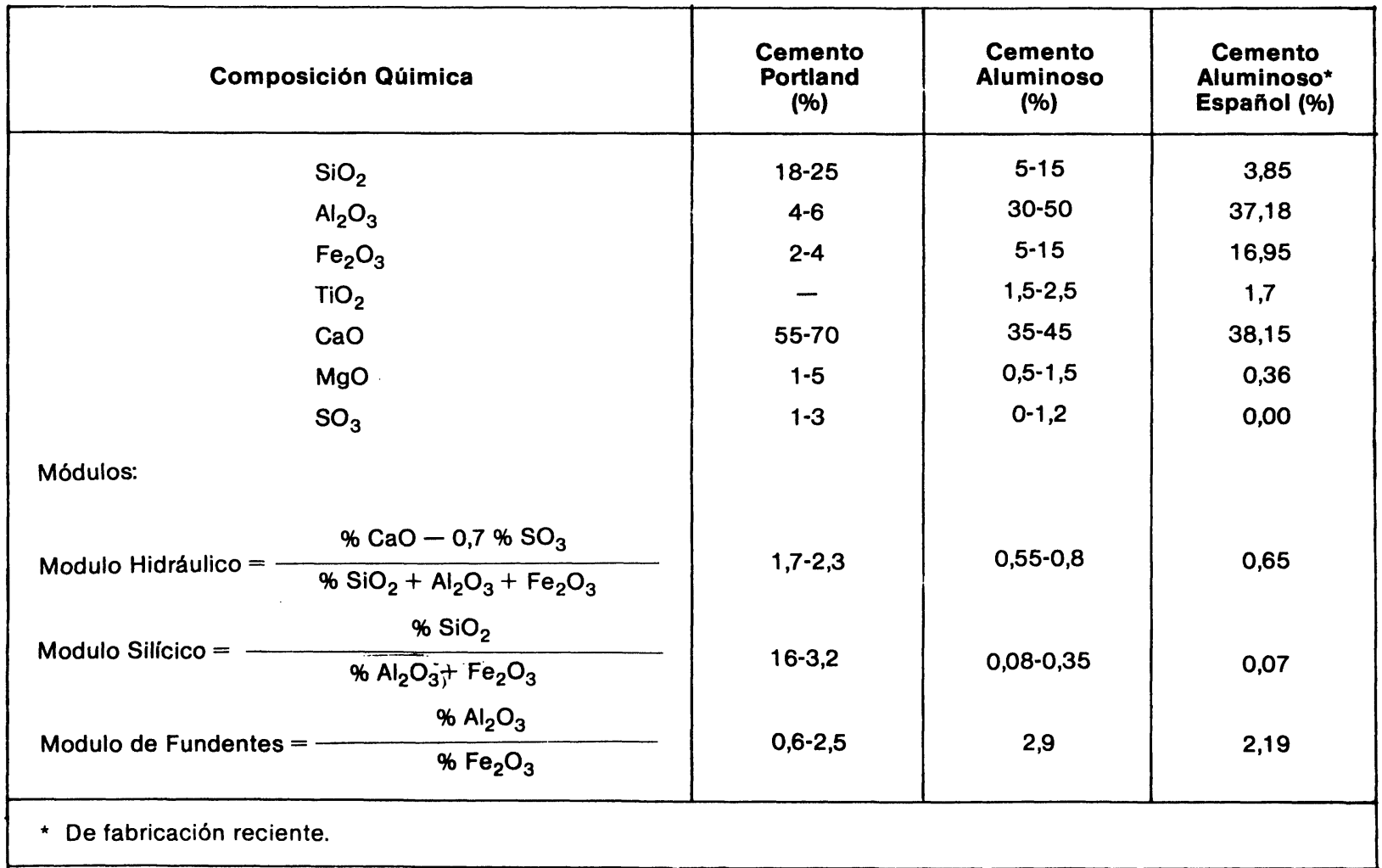


A tal efecto conviene recordar que el $\mathrm{Vm}$ del $\mathrm{CAH}_{10}$ (apartado II) es de 198,80 $\mathrm{cm}^{3}$; el $\mathrm{Vm}$ del $4 \mathrm{CaO} \cdot \mathrm{Al}_{2} \mathrm{O}_{3} \cdot 12 \mathrm{H}_{2} \mathrm{O}$ (apartado II) es de $169,20 \mathrm{~cm}^{3}$; el $\mathrm{Vm}$ del $3 \mathrm{CaO} \cdot \mathrm{Al}_{2} \mathrm{O}_{3} \cdot 6 \mathrm{H}_{2} \mathrm{O}$ (apartado II) es de 149,98 $\mathrm{cm}^{2}$, mientras que el $\mathrm{Vm}$ del silicato de calcio hidratado $3 \mathrm{CaO} . \mathrm{SiO}_{2} .2 \mathrm{H}_{2} \mathrm{O} \quad\left(\mathrm{C}_{3} \mathrm{SH}_{2}\right)$ es tan sólo $81,28 \mathrm{~cm}^{3}$, siendo el de la tobermorita $\mathrm{CaO} \mathrm{SiO}_{2} \cdot \mathrm{H}_{2} \mathrm{O}(\mathrm{CSH})$ aún menor.

Los principales minerales constituyentes del clinker del cemento aluminoso son los siguientes: Aluminato Monocálcico: $\mathrm{CaO} \mathrm{Al}_{2} \mathrm{O}_{3}(\mathrm{CA})$; Bialuminato Cálcico: $\mathrm{CaO} .2 \mathrm{Al}_{2} \mathrm{O}_{3}\left(\mathrm{CA}_{2}\right)$; Aluminato Cálcico 12/7: $12 \mathrm{CaO} .7 \mathrm{Al}_{2} \mathrm{O}_{3}\left(\mathrm{C}_{12} \mathrm{~A}_{7}\right.$; Belita: $2 \mathrm{CaO} \mathrm{SiO}_{2}\left(\beta-\mathrm{C}_{2} \mathrm{~S}\right)$ (si el \% $\mathrm{SiO}_{2}<5 \%$ ); Gehlenita: $2 \mathrm{CaO} \cdot \mathrm{Al}_{2} \mathrm{O}_{3} \cdot \mathrm{SiO}_{2}$ (si el \% $\mathrm{SiO}_{2}>$ $>5 \%)\left(\mathrm{C}_{2} \mathrm{AS}\right)$; Browmillerita: $4 \mathrm{CaO} \cdot \mathrm{Al}_{2} \mathrm{O}_{3} . \mathrm{Fe}_{2} \mathrm{O}_{3}$ $\left(\mathrm{C}_{4} \mathrm{AF}\right)$, destacando cuantitativamente de entre todos ellos el Aluminato Monocálcico: CA.

En la composición del cemento aluminoso -en contraposición a lo que ocurre en el cemento portland- pueden existir variaciones muy considerables de composición química $y$ mineralógica, sin que por ello varien las propiedades de dicho cemento, siendo no obstante la más importante y común de todas ellas el que la relación $\mathrm{Al}_{2} \mathrm{O}_{3}$. $\mathrm{CaO}$ se encuentre entre 4,85 y 1,3 , como asi ocurre.

El cemento aluminoso obtenido por sinterización contiene, principalmente, $\mathrm{Al}_{2} \mathrm{O}_{3}$ y $\mathrm{CaO}$, y cantidades menores de $\mathrm{SiO}_{2}, \mathrm{Fe}_{2} \mathrm{O}_{3}, \mathrm{MgO}$ y $\mathrm{TiO}_{2}$, careciendo por completo de cal libre.

Por otra parte el hierro contenido en el cemento aluminoso se encuentra en un estado reducido. El contenido en hierro del cemento aluminoso sinterizado se encuentra, a veces, formando compuestos ferrosos. La oxidación del hierro reducido va acompañada de una coloración del cemento, pero también se origina un cambio de color cuando se forman compuestos férricos en la hidratación. En cierto modo, estos cambios de coloración son las manifestaciones de transformaciones que tienen lugar en el cemento fraguado.

En España existe una sola fábrica de cemento aluminoso, una de cuyas composiciones quimicas relativamente recientes se puede ver en la Tabla I.

Fundamentalmente se debe decir que existen, al parecer, dos tipos de cemento aluminoso (según SOLACOLU y TALABER):

- el cemento aluminoso Tipo I que contiene, principalmente, $C A$ y $C_{12} A_{7}$ y que origina una más elevada resistencia mecánica a edades iniciales; $y$
- el cemento aluminoso Tipo II que contiene, principalmente, $\mathrm{CA}$ y $\mathrm{CA}_{2}$ y que origina una baja resistencia mecánica inicial, pero una secundaria más intensa.

\section{HIDRATACION DEL CEMENTO ALUMI- NOSO}

Nos dice Lafuma que en las condiciones ordinarias de presión y temperatura se admite la existencia de una serie de aluminatos de calcio hidratados, cristalizados en formas hexagonales o pseudo-hexagonales (en placas, láminas o laminillas).

$$
\begin{array}{ll}
\text { CaO.Al } \mathrm{O}_{3} .10 \mathrm{H}_{2} \mathrm{O} & \text { ó } \mathrm{CAH}_{10} \\
2 \mathrm{CaO} . \mathrm{Al}_{2} \mathrm{O}_{3} .8 \mathrm{H}_{2} \mathrm{O} & \mathrm{C}_{2} \mathrm{AH}_{8} \\
3 \mathrm{CaO} . \mathrm{Al}_{2} \mathrm{O}_{3} .12 \mathrm{H}_{2} \mathrm{O} & \mathrm{C}_{3} \mathrm{AH}_{12} \\
4 \mathrm{CaO} . \mathrm{Al}_{2} \mathrm{O}_{3} .12 \mathrm{H}_{2} \mathrm{O} & \mathrm{C}_{4} \mathrm{AH}_{12} \\
6 \mathrm{CaO} . \mathrm{Al}_{2} \mathrm{O}_{3} .30 \mathrm{H}_{2} \mathrm{O} & \mathrm{C}_{6} \mathrm{AH}_{30}
\end{array}
$$

y del aluminato hidratado cúbico,

$$
3 \mathrm{CaO} . \mathrm{Al}_{2} \mathrm{O}_{3} .6 \mathrm{H}_{2} \mathrm{O} \text { ó } \mathrm{C}_{3} \mathrm{AH}_{6}
$$

y recuérdese también que los aluminatos hexagonales son METAESTABLES, es decir, que en medio acuoso pueden transformarse a la larga en aluminato cúbico, que es la única forma estable a la temperatura ordinaria; dicha transformación es lenta por debajo de $25^{\circ} \mathrm{C}$, pero acelerada por la elevación de la temperatura y las concentraciones en cal, o en alcalinos, $\mathrm{Na}^{+}, \mathrm{K}^{+}, \mathrm{NH}_{4}{ }^{+}$, etc., de la disolución en contacto con la cual se encuentran.

Otros compuestos que se pueden originar de la hidratación del cemento aluminoso son:

- El Hidróxido de Aluminio $\mathrm{Al}(\mathrm{OH})_{3}$ ó $\mathrm{AH}_{3}$, que es un compuesto que aparece como un producto directo de la hidratación del $\mathrm{CA}_{2}$ o como resultado de la evolución del $\mathrm{CAH}_{10}$, o mejor quizás $\mathrm{CAH}_{\mathrm{x}}$, hacia aluminatos cálcicos hidratados más básicos $\left(\mathrm{C}_{2} \mathrm{AH}_{8}\right.$ y $\left.\mathrm{C}_{3} \mathrm{AH}_{6}\right)$. El $\mathrm{AH}_{3}$ en las primeras etapas de su formación probablemente está en forma de gel que evoluciona rápidamente hacia la forma cristalina de gibbisita o $\gamma$-Al( $(\mathrm{OH})_{3}$, con o sin las etapas intermedias de boehmita $[\gamma-\mathrm{AlO}(\mathrm{OH})]$ y/o bayerita $\left[\alpha-\mathrm{Al}(\mathrm{OH})_{3}\right]$.

- Los Carboaluminatos, los cuales se forman generalmente al estar expuesto el cemento aluminoso, en las condiciones normales de servicio, en contacto con el aire, y más concretamente con el $\mathrm{CO}_{2}$ del mismo; existen varios tipos de carboaluminatos. 
Por ultimo señalaremos, entre los compuestos hidratados del cemento aluminoso: la Tobermorita $\mathrm{CSH}$, la Gehlenita $\mathrm{C}_{2} \mathrm{ASH}_{8}$, y una serie de disoluciones sólidas de composición entre el $\mathrm{C}_{3} \mathrm{AH}_{6}$ y el $\mathrm{C}_{4} \mathrm{FH}_{6}$ y geles de hidróxido de hierro, que son productos de hidratación que proceden de la hidratación del $\mathrm{C}_{4} \mathrm{AF}$.

\section{LA TRANSFORMACION O "CONVER- SION" DEL CEMENTO ALUMINOSO: FACTORES QUE LA AFECTAN}

Puesto que en el diagrama $\mathrm{CaO}-\mathrm{Al}_{2} \mathrm{O}_{3}-\mathrm{H}_{2} \mathrm{O}$ la única fase estable a la temperatura ordinaria del cemento aluminoso es el aluminato cúbico $\mathrm{C}_{3} \mathrm{AH}_{6}$, todas las fases metaestables hexagonales (laminillas) descritas en el apartado $\mathrm{II}$, tienden a transformarse más pronto o más tarde en la fase estable cúbica (cristal) con liberación simultánea de hidróxido de aluminio $\mathrm{AH}_{3}$ y agua, según las siguientes reacciones:

$$
\begin{gathered}
3 \mathrm{CAH}_{10} \rightarrow \mathrm{C}_{3} \mathrm{AH}_{6}+2 \mathrm{AH}_{3}+18 \mathrm{H}_{2} \mathrm{O} \\
3 \mathrm{C}_{2} \mathrm{AH}_{8} \rightarrow 2 \mathrm{C}_{3} \mathrm{AH}_{6}+\mathrm{AH}_{3}+\mathrm{H}_{2} \mathrm{O}
\end{gathered}
$$

Estas transformaciones originan una disminución del volumen del sólido cementante de un $40 \%$, lo que da lugar a una elevación importante de la porosidad que va acompañada de una disminución notable de resistencia mecánica - del $75 \%$ en forma de mortero $u$ hormigón y del $15 \%$ al $20 \%$ en forma de pasta-y de resistencia frente a la corrosión del hormigón de cemento aluminoso con el que se haya confeccionado una determinada estructura, así como también de sus armaduras metálicas y en definitiva al colapso, más pronto o más tar de, de la misma, según las condiciones del medio que la rodean.

Por lo tanto dicha transformación se adscribe a las siguientes causas:

a) Rotura mecánica de los enlaces del cemento aluminoso correspondientes al $\mathrm{CAH}_{10}$, por la desaparición de dicha compuerta.

b) Fuerza de ligazón de la mezcla $\mathrm{C}_{3} \mathrm{AH}_{6}+$ $+\mathrm{AH}_{3}$, inferior a la del $\mathrm{CAH}_{10}$.

c) Aumento de la porosidad debido a la formación y evaporación del agua.

Parece existir pruebas de que la última de estas causas es la que más contribuye a la disminución notable de resistencias mecánicas.
Así, si el fraguado del cemento aluminoso tiene lugar a unos $20^{\circ} \mathrm{C}$ debido al calor de hidratación, la roca de cemento se calienta pudiendose transformar los compuestos hidratados que se fisuraron en primera instancia mucho más pronto. $Y$ en la práctica esto trae como consecuencia el que, cuando añadimos al cemento toda el agua necesaria para la hidratación, el agua que se libera después al salir de la roca de cemento, secada al aire, origina un producto muy poroso que es desfavorable desde el punto de vista de la tenacidad y de la corrosión, y en ocasiones peligroso para la vida humana. Por tanto la utilización para el amasado de relaciones a/c $<0,4$ se preconiza actualmente como remedio para evitar o reducir al máximo esta pérdida de resistencias mecánicas. Con ello se pretende que quede una cantidad de cemento anhidro suficiente para fijar, por hidratación ulterior, el agua librada en la "conversión" hexagonal/cúbico, y evitar así el aumento de porosidad.

De todo ello puede decirse con fundamento que, de los FACTORES que afectan a la transformación o "conversión", tanto la velocidad de conversión de los aluminatos hexagonales en cúbicos, como la evolución del gel de alúmina metaestable hacia gibsita, $\gamma-\mathrm{Al}(\mathrm{OH})_{3}$ bien cristalizada aumentan al crecer la temperatura $y$ el $\mathrm{pH}$ del medio, ejerciendo además la humedad ambiental una gran influencia en la velocidad de conversión, de tal forma que ésta se reduce mucho en ambiente seco, aun a altas temperaturas.

Asimismo, el tamaño de los cristales y el grado de ordenación de los hidratos tienen un efecto considerable en la velocidad de conversión; de aqui que los hidratos hexagonales desarrollados a bajas temperaturas y dejados madurar a estas bajas temperaturas presentan una velocidad de conversión mucho mas reducida, aun en condiciones favorables a la conversión (altas temperaturas y humedades), que los hidratos hexagonales no madurados, que suele ser como se presentan en la mayoría de las ocasiones donde se ha originado la degeneración del cemento aluminoso por "conversión".

Se debe indicar que la transformación o "conversión" - hexagonal (metaestable) $\rightarrow$ cúbico (estable) - del cemento aluminoso no se produce siempre, pero siempre es posible, y se puede resumir mediante las siguientes reacciones esquemáticas:
Cemento Aluminoso$$
+ \text { Humedad }\left(\mathrm{H}_{2} \mathrm{O}\right)
$$
Hidratado Hexagonal $\mathrm{CAH}_{10}$ $\mathrm{C}_{3} \mathrm{AH}_{6}$
(en ausencia de $\left.\mathrm{CO}_{2} \mathrm{y} / \mathrm{o} \mathrm{CO}_{3} \mathrm{Ca}\right)+$ Calor 


\section{LA "CARBONATACION" DEL CEMEN- TO ALUMINOSO}

El anhidrido carbónico $\mathrm{CO}_{2}$ del aire $(0,053 \%$ en peso y $0,035 \%$ en volumen) ataca a los aluminatos cálcicos, es decir, la piedra de cemento húmeda absorbe dióxido de carbono, siendo probable que se formen inicialmente aluminatos de calcio hidratados complejos que contengan $\mathrm{CO}_{3} \mathrm{Ca}$, aunque mediante más absorción de $\mathrm{CO}_{2}$ se forma también calcita e hidrargilita.

No obstante las últimas investigaciones realizadas al respecto en el ICCET por Gauna, Triviño y Vázquez, han puesto de manifiesto que:

a) El cemento aluminoso anhidro es capaz de carbonatarse lentamente con el transcurso del tiempo y mucho más rápidamente en las primeras horas de amasado. Esta carbonatación - aunque pequeña cuantitativamente - influye de forma apreciable, tanto en la velocidad de hidratación, a la que reduce, como en la naturaleza de los componentes hidratados formados. d) La formación de carboaluminatos disminuye o inhibe parcialmente la transformación hexagonal a cúbico del cemento aluminoso, pero no impide su degradación por el anhidrido carbónico, $\mathrm{CO}_{2}$, del aire en presencia de humedad. El punto final de esta degradación está constituido por una mezcla de $\mathrm{CaCO}_{3}$, óxido de aluminio, $\mathrm{Al}_{2} \mathrm{O}_{3} \mathrm{e}$ hidróxido de aluminio $\mathrm{Al}(\mathrm{OH})_{3}$.

e) La degradación del cemento aluminoso, como consecuencia de la transformación de las fases hexagonales en la fase cúbica, es favorecida y llevada a su etapa final por el anhídrido carbónico en medio húmedo. La etapa final de la degradación del cemento aluminoso comporta la destrucción de la propia fase cúbica y está constituida por: aragonito, $\mathrm{CaCO}_{3}$, fina y homogéneamente dispersa, en una matriz de alúmina anhidra.

f) La fuerte desecación hasta la casi tota eliminación de la clase más lábil del agua de cristalización del aluminato monocálcico hidratado, estabiliza a éste frente a la temperatura y al $\mathrm{CO}_{2}$, en ambiente seco.

Todas ellas se pueden resumir en las reacciones esquemáticas siguientes:

Cemento Aluminoso $\quad+$ Humedad $\left(\mathrm{H}_{2} \mathrm{O}\right) \quad+$ Aire $\left(\mathrm{CO}_{2}\right)+\operatorname{Humedad}\left(\mathrm{H}_{2} \mathrm{O}\right)$ No conglomerantes

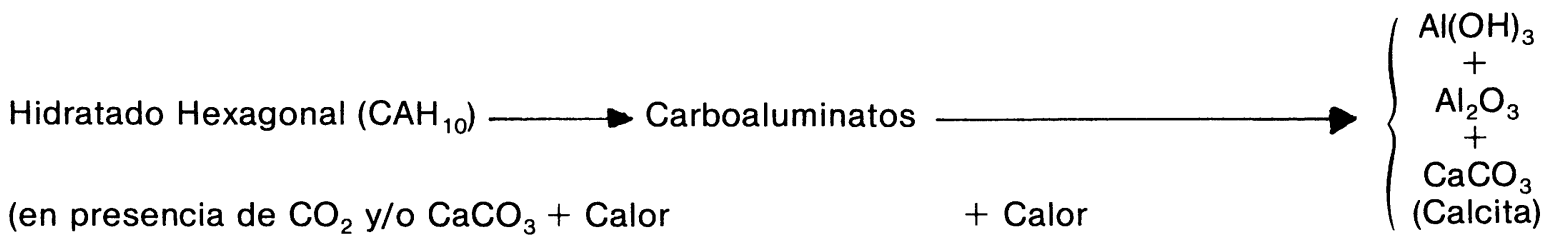

b) La hidratación a baja temperatura $\left(1^{\circ}\right.$ a $\left.4^{\circ} \mathrm{C}\right)$ de cementos aluminosos meteorizados, o de cementos no meteorizados amasados en ambiente contaminado por $\mathrm{CO}_{2}$, desarrolla fases hexagonales que retienen de alguna manera el $\mathrm{CO}_{2}$ incluso en su masa y son menos cristalinas que las correspondientes en ausencia de $\mathrm{CO}_{2}$. Al someter estos cementos hidratados a las condiciones adecuadas para la transformación hexagonal/cúbica (alta temperatura y humedad), la transformación transcurre hacia la formación de monocarboaluminatos con preferencia a la de aluminatos cálcicos cúbicos.

c) La hidratación a temperaturas medias $\left(20^{\circ}\right)$ $y$ altas $\left(40^{\circ}\right)$ de los cementos aluminosos aludidos en b) y la de las mezclas de cemento aluminoso con $\mathrm{CaCO}_{3}$ finamente pulverizada, desarrolla fases cúbicas $\left(\mathrm{C}_{3} \mathrm{AH}_{6}\right)$ en cantidad inferior a la normal en ausencia de $\mathrm{CO}_{2}$ ó $\mathrm{CaCO}_{3}$ y en favor de los monocarboaluminatos.

\section{LA "HIDROLISIS ALCALI-CARBONICA" DEL CEMENTO ALUMINOSO}

Los carbonatos alcalinos tales como $\mathrm{Na}_{2} \mathrm{CO}_{3}$, $\mathrm{K}_{2} \mathrm{CO}_{3}$, reaccionan con los aluminatos de calcio hidratados en el cemento aluminoso según las siguientes reacciones:

a) Hidrólisis alcalina de los aluminatos de calcio hidratados:

$$
\begin{aligned}
& \mathrm{Na}_{2} \mathrm{CO}_{3}+\mathrm{Al}_{2} \mathrm{O}_{3} \cdot \mathrm{CaO} \cdot 10 \mathrm{H}_{2} \mathrm{O} \rightarrow \\
& \mathrm{CaCO}_{3}+\mathrm{Al}_{2} \mathrm{O}_{3} \cdot \mathrm{Na}_{2} \mathrm{O}^{\star}+10 \mathrm{H}_{2} \mathrm{O}
\end{aligned}
$$

b) Regeneración del carbonato alcalino al penetrar superficialmente $\mathrm{CO}_{2}$ atmosférico en la pieza de hormigón:

$$
\begin{gathered}
\mathrm{CO}_{2} \text { (aire) }+\mathrm{Al}_{2} \mathrm{O}_{3} \cdot \mathrm{Na}_{2} \mathrm{O}+3 \mathrm{H}_{2} \mathrm{O} \rightarrow \\
\mathrm{Na}_{2} \mathrm{CO}_{3}+\mathrm{Al}_{2} \mathrm{O}_{3} \cdot 3 \mathrm{H}_{2} \mathrm{O}
\end{gathered}
$$

\footnotetext{
* Soluble en agua y, por tanto, no conglomerante.
} 
c) $\mathrm{CO}_{2}$ (aire) $+\mathrm{Al}_{2} \mathrm{O}_{3} \cdot \mathrm{CaO} \cdot 10 \mathrm{H}_{2} \mathrm{O} \rightarrow \mathrm{CaCO}_{3}+$ $+\mathrm{Al}_{2} \mathrm{O}_{3} .3 \mathrm{H}_{2} \mathrm{O}+7 \mathrm{H}_{2} \mathrm{O}$ con lo que gracias al $\mathrm{CO}_{2}$ atmosférico, se verifican las reacciones b) y c), regenerándose en la b) el carbonato alcalino, origen y motivo del ataque y degradación del cemento aluminoso hidratado constitutivo del hormigón correspondiente deteriorado; pudiéndose decir por tanto con fundamento que todo sucede como si el aluminato de calcio hidratado hubiese sido descompuesto por $\mathrm{CO}_{2}$, según la reacción $\mathrm{c}$ ), interviniendo tan sólo el carbonato alcalino $\mathrm{Na}_{2} \mathrm{CO}_{3}$ como intermediario para que la reacción se efectúe en condiciones en que la cohesión y tenacidad del hormigón desaparecen.

Dicho proceso cíclico degenerativo finalizará cuando todos los aluminatos de calcio hidratados hayan desaparecido al haber sido fijados de forma gradual y lentamente por el $\mathrm{Na}_{2} \mathrm{CO}_{3}, \mathrm{~K}_{2} \mathrm{CO}_{3} \mathrm{u}$ otros carbonatos alcalinos.

En definitiva, el carbonato alcalino actúa como el vínculo que promueve el ataque por el anhidrido carbónico $\mathrm{CO}_{2}$ del aire atmosférico.

No obstante dicho proceso degenerativo, así expuesto y simbolizado por las tres reacciones anteriores, podría muy bien llegar a confiar al proyectista o respondable máximo de la obra civil realizada, en mayor o menor medida con hormigón de cemento aluminoso, al considerar erroneamente que nadie en su obra va a echar a propósito $\mathrm{Na}_{2} \mathrm{CO}_{3}, \mathrm{~K}_{2} \mathrm{CO}_{3}$, u otros carbonatos alcalinos u otras sales alcalinas, ni la misma se encuentra o va a encontrarse próxima a industrias químicas o aguas residuales con tales agresivos... $Y$ es que tales agresivos pueden acabar por mostrar su agresividad al hormigón de cemento aluminoso con el que la misma se ha ejecutado, sin más que las aguas de amasado $y / 0$ los áridos gruesos o finos constitutivos del mismo los aporten, no como tales, sino como otros componentes minerales alcalinos diversos más o menos solubles o lixiviables, respectivamente.

Así por ejemplo, en 1927, Freyssinet y Goyne observaron en hormigones de cemento aluminoso amasados con agua de mar -que poseen cloruro sódico $\mathrm{NaCl}$ y cloruro potásico $\mathrm{KCl}$ - una falta absoluta de endurecimiento acompañada de una coloración amarillenta, fenómeno al que denominaron por entonces genéricamente "la enfermedad del cemento aluminoso". E igualmente puede llegar a ocurrir si, pese a haber preparado el hormigón de cemento aluminoso con agua potable y árido silícico exentos de esos u otros cationes alcalinos, la pieza estructura, obra civil o de edificación correspondiente, va a estar en contacto permanente con humedades y nieblas marinas, en cuyo caso tales cationes alcalinos serian de origen exógeno para diferenciarlos de los anteriores que serian de origen endógeno.

De ahí que los climas tropicales y subtropicales -como pueden ser en España las Islas Canarias, Baleares y costas peninsulares, de clima mediterráneo mayormente-, les afecten tanto a los hormigones de cemento aluminoso, pese a su adecuada y perfecta ejecución.

No obstante tales cationes alcalinos, $\mathrm{Na}^{+}, \mathrm{K}^{+}$, etc., también pueden provenir de otros conglomerantes en contacto con los cuales se encuentra el hormigón de cemento aluminoso, y/o también de los propios áridos del hormigón, si los mismos los poseen en su constitu ción una forma soluble o lixiviable por disoluciones básicas, como pueden ser los casos de ciertas rocas ígneas, plutónicas, basálticas, metamórficas, etc.; por esta razón es importan te que los áridos de machaqueo de rocas ígneas, que se empleen en preparar hormigón de cemento aluminoso, estén libres de finos (polvo fino) que pueden liberar alcalinos.

Conviene recordar, además, que según Lafuma las disoluciones muy concentradas de alcalinos $\mathrm{Na}^{+}, \mathrm{K}^{+}$, etc. favorecen, en ausencia de toda evaporación o carbonatación, la transformación o "conversión" RAPIDA del aluminato de calcio hidratado hexagonal en aluminato cúbico.

\section{LA CORROSION DE LAS ARMADURAS EN EL HORMIGON DE CEMENTO ALUMINOSO. CENERALIDADES}

Lafuma dice que el endurecimiento del cemento aluminoso tras su amasaso con agua, y más concretamente de su componente hidráulico más característico y abundante como es el $\mathrm{CaO} . \mathrm{Al}_{2} \mathrm{O}_{3}(\mathrm{CA})$, se efectúa sin liberación de hidróxido de Calcio, $\mathrm{Ca}(\mathrm{OH})_{2}$ según la reacción:

$$
\mathrm{CaO} . \mathrm{Al}_{2} \mathrm{O}_{3}+10 \mathrm{H}_{2} \mathrm{O} \rightarrow \mathrm{CaO} \mathrm{Al}_{2} \mathrm{O}_{3} \cdot 10 \mathrm{H}_{2} \mathrm{O}
$$

siendo tal hecho una de las diferencias más notables con el cemento portland, en el que ocurre todo lo contrario en tales circunstancias, o sea, liberación de $\mathrm{Ca}(\mathrm{OH})_{2}$, según la reacción siguiente: u otras similares.

$$
\begin{gathered}
3 \mathrm{CaO}^{\mathrm{SiO}} \mathrm{Si}_{2}+\mathrm{nH}_{2} \mathrm{O} \rightarrow \\
2 \mathrm{CaO} . \mathrm{SiO}_{2} \cdot \mathrm{H}_{2} \mathrm{O}+\mathrm{Ca}(\mathrm{OH})_{2}
\end{gathered}
$$

De todos es conocido que un notable exceso de $\mathrm{Ca}(\mathrm{OH})_{2}$ aumenta y faborece la protección -durabilidad-de las armaduras metálicas del homigón armado de cemento portland, en detrimento de su propia durabilidad química ante 
el ataque de los sulfatos y aguas muy puras y con $\mathrm{CO}_{2}$ agresivo, mayormente, y viceversa, que es lo que ocurre en el caso del cemento aluminoso.

Por otra parte también de todos es conocido que el grado de protección de la armadura de un hormigón armado depende, entre otras causas, del tipo de cemento que se ha empleado para su preparación, siendo por lo general mayor la que confiere el cemento portland, seguido de los cementos siderúrgicos y de los puzolánicos, por este orden, de mayor a menor grado de protección. $Y$ ello debido por lo general, y entre otras causas, a que la reserva alcalina o mejor reserva de portlandita, $\mathrm{Ca}(\mathrm{OH})_{2}$, es mayor en los cementos portland que en los siderúrgicos, y en éstos mayor que en los puzolánicos.

Así, por ejemplo, si un cemento portland posee un $62 \%$ de $\mathrm{CaO}$ [valor medio aproximado entre los extremos posibles $55 \%$ y $70 \%$ de los cementos portland (Tabla 1)], y al mismo se le adiciona un $35 \%$ de puzolana natural o ceniza volante, el cemento puzolánico anhidro resultante tendría un contenido aproximado de $\mathrm{CaO}$ (que provendría de su fracción portland) del 40,3 \%. Y el contenido de $\mathrm{CaO}$ del ejemplo expuesto de cemento aluminoso en la Tabla 1 es del $38,15 \%$, pudiendo existir incluso cementos aluminosos cuyo contenido en $\mathrm{CaO}$ llegue a ser del $35 \%$ o quizas aún menor. De lo cual podria decirse, con fundamento, que la protección que el cemento aluminoso puede llegar a proporcionar a las armaduras pudiera llegar a ser equiparable, en el origen, a la de un cemento puzolánico en iguales circunstancias, con el agravante para el aluminoso que con toda probabilidad su hormigón resultante sería además menos compacto que el del puzolánico, dado que la notable finura de la puzolana y sus productos de hidratación resultantes - silicatos de calcio hidratados, en su mayor parte lógicamente, que sobre todo son más estables y durables que los aluminatos de calcio hidratados hexagonales del cemento aluminoso-, proporcionan una menor porosidad del hormigón y una mayor protección física de las armaduras, coadyuvante de la química correspondiente, la cual puede no llegar a ser suficiente en el tiempo para proporcionar una gran DURABILIDAD en el caso de utilización "Irresponsable" de las puzolanas y/o de los cementos portland con puzolanas. Debido a lo expuesto, no es de extrañar la reciente aparición de diversas estructuras de hormigón de cementos puzolánicos PUZ y/o de cemento portland con adiciones puzoláni cas, PA, deterioradas muy seriamente por carbonatación. Tales cementos PA se comenzaron a fabricar y comercializar en españa a partir del año 1975, lo cual es toda una prueba determinante.

De esta forma la realidad ha demostrado lo razonable de la hipótesis expuesta, así como también la nocividad de la carbonatación, no sólo indirectamente para las armaduras metálicas del hormigón, sino también directamente para el propio cemento aluminoso, PA ó PUZ, que lo constituya, cuya degradación resulta ser al final semejante, aunque a través de reacciones químicas diferentes, dadas las composiciones químicas y constitución mineralógica notablemente distintas de ambos conglomerantes hidráulicos.

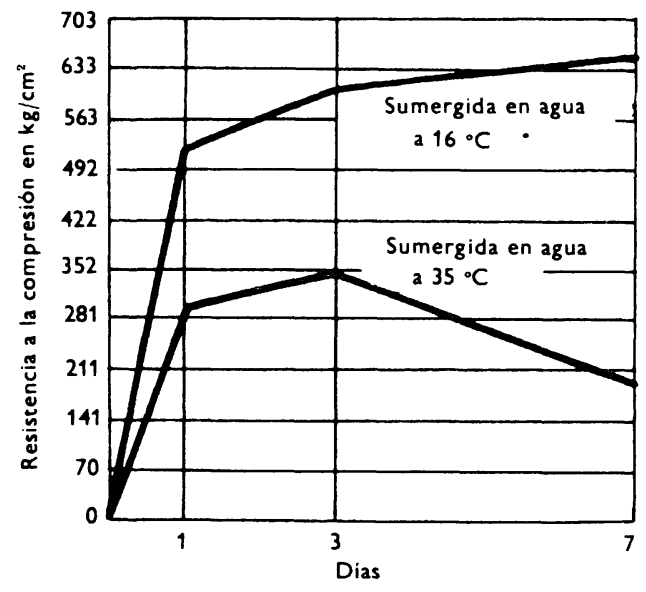

Fig. 1.-Influencia de la temperatura en la resistencia a la compresión en cementos fundidos de alúmina (Lea, Desch, 1946).

Si a todo ello añadimos que las tres "enfermedades" características del cemento aluminoso se verifican con pérdida sustancial paulatina y en distinto grado de grupos $\mathrm{OH}^{-}$-derivados de la hidratación anterior del cemento aluminoso-, conforme se desarrollan y evolucionan las enfermedades resultará, finalmente, que la protección de las armaduras disminuirá con el tiempo, pudiendo incluso llegar a ser nula. De lo expuesto no es de extrañar que según sea su diámetro y el tiempo transcurrido lleguen a "desaparecer" las enfermedades, no dejando ni "huella" de su presencia anterior (fotos 5 y 12).

Por último, se ha de advertir en este apartado que las armaduras tensadas del hormigón de cemento aluminoso están muy amenazadas por la corrosión, debiendo contarse con un incremento de dicha corrosión en baños, aseos, saunas y similares y no, por el contrario, en las habitaciones interiores más secas de la vivienda. Además, tales procesos corrosivos de las armaduras vienen acompañados generalmente por un descenso apreciable de resistencias mecánicas del hormigón de cemento aluminoso. 
VII. LA “ALUMINOSIS" DEL CEMENTO ALUMINOSO O UN TERMINO NUEVO A UNA CLASICA ENFERMEDAD

De lo anterior expuesto en los apartados III, IV y $\mathrm{V}$, y de la realidad geoclimática española, cabe deducir con fundamento lo siguiente:

1. Que las tres "enfermedades" características del cemento aluminoso conversión, carbonatación e hidrólisis álcali-carbónica si bien pueden originarse en el cemento aluminoso de forma individualizada, lo normal es que se originen, en su caso, de forma conjunta, o mejor quizás de forma conjuntada, queriendo significar en esta palabra que puede haber una cierta sincronia entre ambas, ya sean tres o sólo dos las que se verifiquen, o mejor aún, un cierto orden a la hora de su génesis y evolución con solapamiento inclusive entre ellas.

2. Que de las tres, tan sólo la primera, o sea, la conversión:

- puede llegar a generarse en solitario;

- puede llegar a desarrollarse más pronto, y

- puede llegar a evolucionar con mayor velocidad, en definitiva,

que el resto, si las condiciones del medio les son propicias para ello pudiendo, incluso en ocasiones, generarse y desarrollarse sus fatales consecuencias de un modo muy rápido, violento, espectacular y alarmante, ya que se colapsa la estructura con roturas y hundimien to de las obras, de forma repentina y catastrófica inclusive, $o$ al menos que la permanencia de los inquilinos en sus viviendas puede resultar arriesgada.

Ello se traduce en que si las fatales consecuencias de la "conversión" pueden presentarse a los pocos años de ejecutada la obra, e incluso en ocasiones con bastante anterioridad, las derivadas de la carbonatación y de la hidrólisis alcali-carbónica se pueden presentar y presentan entre los 15 ó 25 años, según sea el grado de agresividad del medio natural que las rodea en cada caso.

De todas ellas pueden derivarse, además, pérdidas de vidas humanas en ocasiones, aunque lógicamente y con mayor probabilidad en el caso de la conversión que en el resto, pudiéndose observar previamente por lo común en todas ellas el lento y progresivo origen y desarrollo de los desperfectos, entre los que cabe citar las fisuraciones notables con pérdida de material y de las armaduras (para entonces total o casi totalmente corroidas), junto a diversas extrañas coloraciones como pueden ser las amarillentas rojizas o sonrosadas - en lugar del color marrón característico de estos hormigones-, las cuales van ligadas a la oxidación del hierro debida a la porosidad subsidiaria generada tras el más o menos lento y progresivo proceso corrosivo y/o degenerativo del cemento aluminoso en cada caso. La aparición de estas coloraciones, según ha demostrado la práctica real, coincide lógicamente con un descenso considerable de los valores de resistencia mecánica del hormigón de cemento aluminoso.

Según lo expuesto anteriormente, y lo sucedido hasta el momento en España en obras civiles $y / 0$ en edificación deteriorada*, y que han sido ejecutadas total o parcialmente con hormigón de cemento aluminoso, ¿a qué proceso(s) corrosivo(s) y/o degenerativo(s) del ce mento aluminoso deberemos y podremos adjudicarle(s) el nombre específico de ALUMINOSIS? En buena lógica habrá de ser necesariamente a la carbonatación e hidrólisis álcalicarbónica mayormente, verificadas de forma individual o conjuntada y con la adicional posible, o no, de la conversión, ya que ambas poseen el requisito previo e imprescindible de generarse, evolucionar y desarrollarse en un largo período de tiempo $(15,20,30$ o más años) que es el condicionante fundamental para poderle adjudicar la denominación de "ALUMINOSIS".

\section{COMPENDIO DE LOS PRINCIPALES MEDIOS AGRESIVOS PARA EL CE- MENTO ALUMINOSO Y FORMAS DE COMBATIRLOS}

\section{A) Principales medios agresivos para el cemento aluminoso}

En definitiva, y por todo lo anteriormente expuesto, se deduce que los principales medios agresivos naturales o artificiales para el cemento aluminoso son los siguientes:

- Las temperaturas elevadas por encima de $20^{\circ} \mathrm{C}$, ya sean durante el amasado o posteriormente.

- Las aguas de amasado con cationes alcalinos o temperaturas superiores a $25^{\circ} \mathrm{C}$.

- La utilización de una relación $a / c>0,4$.

- El anhídrido carbónico $\mathrm{CO}_{2}$ sea cual fuere su origen.

\footnotetext{
* El penúltimo caso se acaba de presentar en las Islas Canarias, en siete mil viviendas de construcción pública y un número indeterminado de construcción privada, en cuya construcción se empleó el cemento aluminoso, y el último caso en Badalona con pérdidas inclusive de vidas humanas.
} 


\section{- Las humedades ambientales elevadas.}

- Las humedades y nieblas marinas, cuya influencia puede llegar a sentirse hasta unos $200 \mathrm{~km}$ del lugar de origen.

- Los cationes alcalinos, tales como $\mathrm{Na}^{+}, \mathrm{K}^{+}$, $\mathrm{NH}_{4}$, etc. procedentes de lejías sódicas y potásicas u otras disoluciones básicas alcalinas.

- Los áridos que poseen tales cationes alcalinos solubles o lixiables por disoluciones básicas; $y$, de entre todos ellos, los áridos finos y ultrafinos (polvos) mayormente.

- Las sales magnéticas, incluso el cloruro y el sulfato magnético.

\section{B) Normas de Buena Práctica para la utili- zación del cemento aluminoso}

1. amasar con un mínimo adecuado de agua descarbonatada, con una relación a/c lo más baja posible, pero en cualquier caso menor de 0,4 , teniéndose en cuenta el proceso de amasado facilitado por la eliminación previa de las partes finas de la arena (ver norma 2.a).

2. Utilizar gravas y arenas limpias -exentas de limos-, arcillas y elementos finos en general y particularmente aportadores de cationes alcalinos liberables. Se evitará el empleo de áridos, arenas y finos que contengan elementos graníticos, esquistos micáceos, feldespáticos, basálticos y similares, en elevado contenido de $\mathrm{Na}^{+}, \mathrm{K}^{+}$, etc.; tampoco calizos ni dolomí ticos. Evitar las partículas inferiores a $0,5 \mathrm{~mm}$ en la arena es la precaución más eficaz.

3. ${ }^{a}$ Hacer un hormigón trabajable y compacto. En ausencia de elementos finos en la arena, la trabajabilidad y la compacidad no pueden obtenerse más que con una dosificación suficiente de cemento aluminoso de 300 a $400 \mathrm{~kg} / \mathrm{m}^{3}$ (función de la granulometría del árido), y con una puesta en obra por vibración o apisonado enérgico.

4. ${ }^{2}$ Es aconsejable efectuar el amasado a baja temperatura $\left(1 \mathrm{a} 4^{\circ} \mathrm{C}\right)$ en ambiente exento de $\mathrm{CO}_{2}$.

5. Evitar una elevación intempestiva de la temperatura y la ausencia, en lo posible, de $\mathrm{CO}_{2}$ durante el curado y el fraguado del mortero u hormigón. La dosificación elevada de cemento hace indispensable el enfriamiento de los morteros y hormigones por riego con agua fría durante las 24 horas siguientes al comienzo del endurecimiento después de la puesta en obra. Si los trabajos han de reali- zarse en tiempo cálido deben adoptarse precauciones especiales, tales como enfriar previamente el agua de amasado y los áridos*.

6. Para evitar la formación inicial de $\mathrm{CO}_{2}-$ hidrogranates $\mathrm{y} / \mathrm{o}$ carbo-aluminatos, gérmenes favorecedores de la acción del $\mathrm{CO}_{2}$ ambiental sobre los hidratos debe evitarse el empleo de cementos aluminosos meteorizados, o largo tiempo almacenados en condiciones inadecuadas.

7. Debe evitarse el empleo de cementos aluminosos en ambientes cálidos, húmedos y contaminados por $\mathrm{CO}_{2}$, por ejemplo: garajes poco aireados, locales donde existen procesos industriales de fermentación (bodegas, lagares, etc.), invernaderos, locales públicos mal ventilados, conducciones de aguas carbonatadas... Especialmente los establos son ejemplos de construcciones en las que este tipo de cemento está contraindicado.

8. Tampoco es recomendable su uso en las zonas del litoral y sus zonas de influencia, particularmente si existen concentraciones favorables.

9. ${ }^{a}$ Como consecuencia de la débil protección alcalina que este cemento ejerce sobre las armaduras, no deben olvidarse las prescripciones relativas a compuestos como cloruros y sulfuros, que pueden favorecer adicionalmente a la corrosión de las mismas.

10. No utilizar para pretensados en ningún caso, ni para temperaturas superiores a $20^{\circ} \mathrm{C}$.

\section{LA RAZON DE SER DEL CEMENTO ALUMINOSO}

El cemento aluminoso tiene su razón de ser en la preparación de hormigones refractarios para resistir temperaturas medias $\left(900^{\circ}\right.$ - $\left.1.000^{\circ} \mathrm{C}\right) \mathrm{o}$ altas $\left(1.400^{\circ}-1.600^{\circ} \mathrm{C}\right)$, dado que en tales circunstancias no presentan ningún proceso degenerativo ni corrosivo. En caso de utilizarse, el árido debe tener propiedades de resistencia al calor, puesto que desempeña una parte importante al determinar la temperatura máximo que el hormigón resistirá. Los áridos más empleados son:

- el ladrillo refractario machacado para temperaturas de hasta $1.300^{\circ}$ a $1.500^{\circ} \mathrm{C}$;

- los ladrillos que contienen más del $40 \%$ de alúmina para temperaturas de hasta 1.300 a $1.500^{\circ} \mathrm{C}$;

\footnotetext{
* No deben utilizarse áridos con hielo o congelados.
} 
- los ladrillos de arcilla corriente para temperaturas de hasta $900^{\circ}$ a $1.000^{\circ} \mathrm{C}$;

- la sillimanita, carborundo, cromo, cromomagnesia, alúmina fundida para temperaturas de hasta $1.400^{\circ}$ a $1.600^{\circ} \mathrm{C}$;

- la diatomita calcinada, vermiculita expandi $\mathrm{da}$, arcilla expandida (en áridos ligeros) para temperaturas de hasta $900^{\circ}$ a $950^{\circ} \mathrm{C}$.

Los hormigones de cemento aluminoso resistentes al calor se emplean en cimientos de hornos, estufas de cok, montaje de calderas, y similares. Los hormigones refractarios son apropiados en hogares y hornos de ladrillo y hornos-túnel, para la tapa de cubierta de vagonetas que entran en dichos hornos, para puertas y revestimientos de hornos, y en hornos eléctricos.

Los morteros refractarios se emplean para unir los ladrillos refractarios y para parches y reparaciones.

\section{$X$. PRESCRIPCIONES Y PROSCRIPCIO- NES DEL CEMENTO ALUMINOSO}

A) Está PRESCRITO (utilizable) para:

- Cimentaciones, fundaciones y apoyos de maquinaria pesada de rápida entrada en servicio.

- Obras de reparación de carácter temporal (de fortificación).

- Obras en terrenos yesíferos y en ambientes o medios ligeramente ácidos.

- Protección interna de tubos metálicos de conducciones de agua potable o potabilizada.

- Taponamiento de vías de agua (mezclado con portland).

- Ciertos elementos prefabricados.

- Hormigones y morteros refractarios.

- Pistas de aterrizaje (desechables a largo uso).

B) Está PROSCRITO (contraindicado) para:

- Casos en que no se pueda garantizar, de manera absoluta, una dosificación suficientemente elevada, una relación agua/cemento adecuadamente baja, unos áridos idóneos en calidad, cantidad y granulometría, y unas condiciones propicias de servicio.

- Mezclas con otros cementos, salvo con portland y exclusivamente para taponamiento de vías de agua.

- Hormigones y morteros en contacto con otros cementos o con medios alcalinos.

- Hormigones y morteros que hayan de estar en contacto con aguas alcalinas cáusticas.

- Elementos de hormigón pretensado; el párrafo tercero del punto 7.1 del Art. $7^{\circ}$, Cap. II de la "Instrucción para el Proyecto y la Ejecución de Obras de Hormịón Pretensado" dice textualmente: "No se utilizará el cemento aluminoso para elementos pretensados...".

\section{CASO REAL DE OBRA DE EDIFICA- CION DETERIORADA, EN ESPAÑA, REALIZADA CON HORMIGON DE CE- MENTO ALUMINOSO}

Con objeto de poder contribuir a un mayor y mejor conocimiento de la sintomatología real de la ALUMINOSIS del cemento aluminoso, a continuación se exponen los detalles y características específicas del deterioro sufrido por unos bloques de viviendas construidos con viguetas de hormigón de cemento aluminoso en una región española, de clima mediterráneo, donde por lo general se da una humedad relativa ambiental potencialmente elevada a lo largo de todo el año, un gradiente térmico muy notable entre el invierno y el verano, y una suave influencia de ambiente marino por su relativa proximidad al mar. Estos bloques de viviendas debieron ser demolidos, hace pocos años, por el peligro que las viviendas llegaron a representar para sus inquilinos. No obstante, los detalles que se exponen de este caso real no deberá inducir a pensar que todas las construcciones realizadas -o por realizarcon hormigón de cemento aluminoso se han deteriorado -o se van a deteriorar- de la misma manera. Existen obras civiles en España de más antigüedad que el caso expuesto y construidas con idéntico conglomerante, las cuales se encuentran en perfecto estado. Esto se debe a que la mayor parte de ellas están situadas, por lo general, en regiones cuya temperatura media anual es de las más bajas de la península (que son las menos) con las consecuencias medioambientales lógicas, coincidiendo sus buenos resultados a los conseguidos en países nórdicos y centroeuropeos con semejante temperatura media anual. 


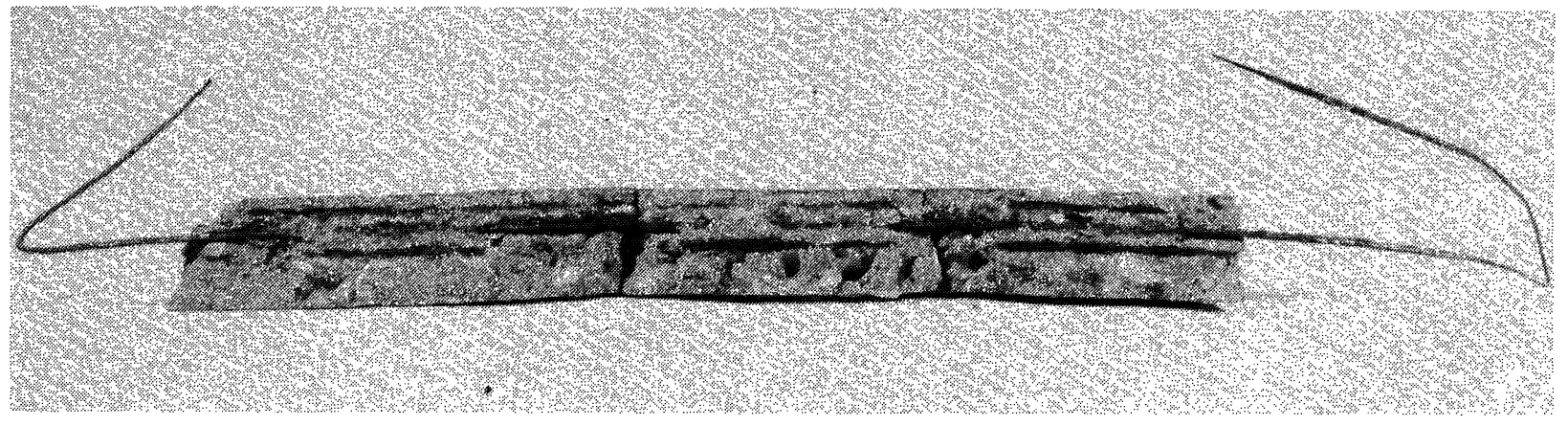

Foto 1.-Fragmento de hormigón desprendido del ala de una de las viguetas. Pueden apreciarse señales del óxido de hierro de las armaduras y disminuciones en la sección de una de ellas.

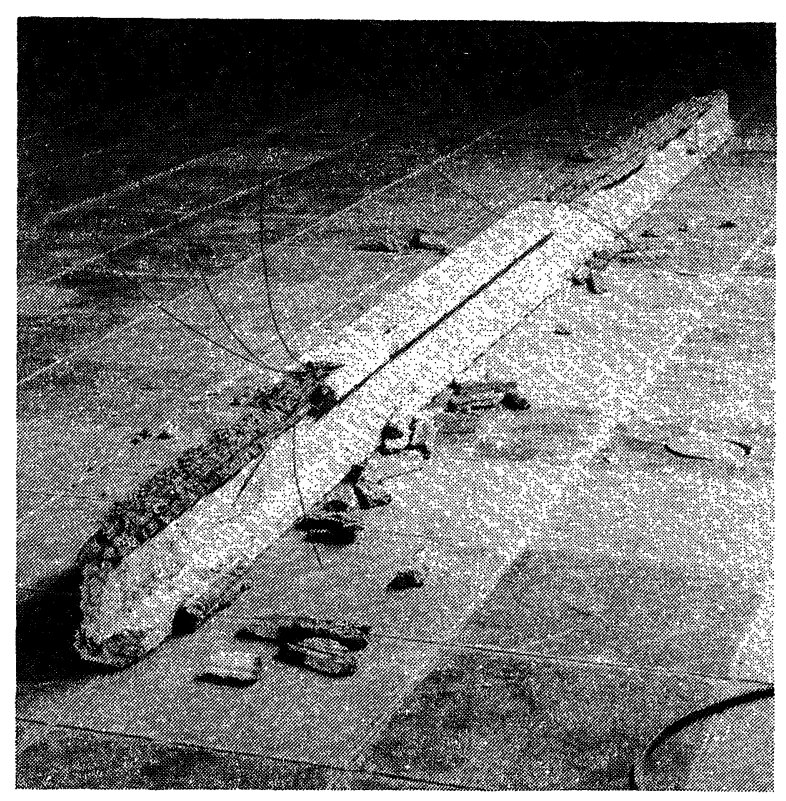

Foto 2.-Estado de una de las viguetas de la cubierta. Puede apreciarse la disgregación del hormigón.

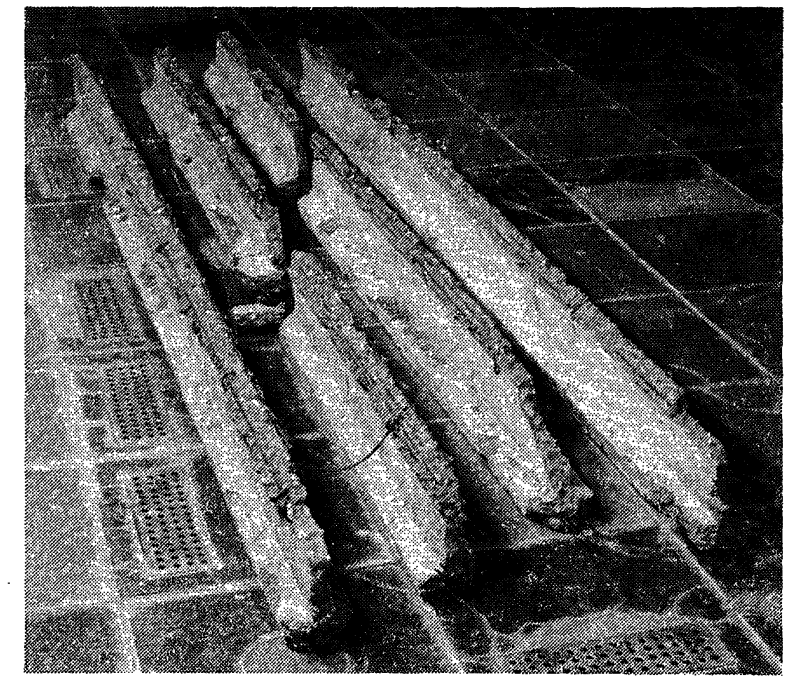

Foto 3.-Estado que ofrecen otros fragmentos de viguetas. Puede apreciarse la cabeza de hormigón totalmente disgregado y las señales de óxido de las armaduras.

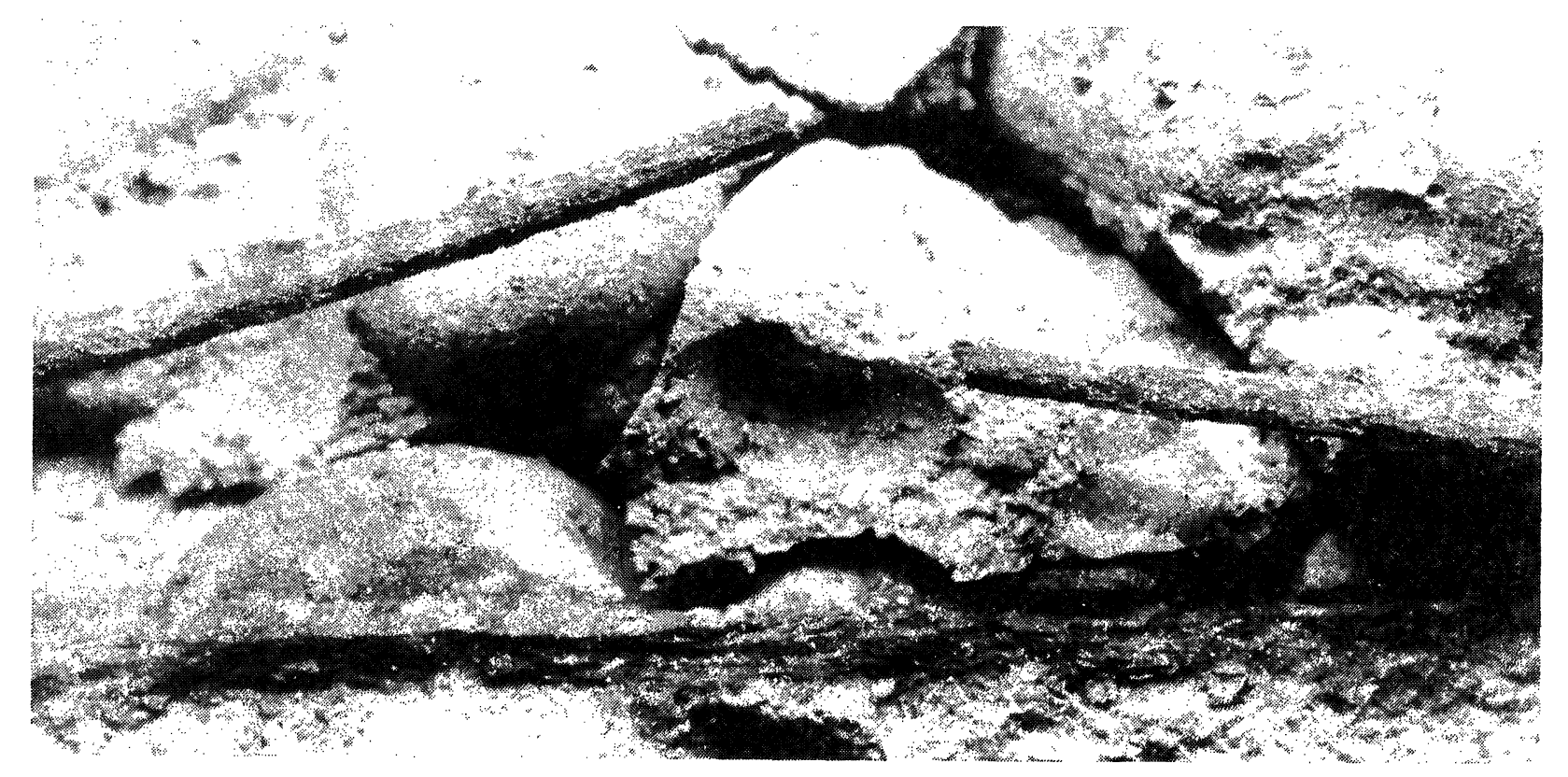

Foto 4.-Detalle del estado que presentan las armaduras. 


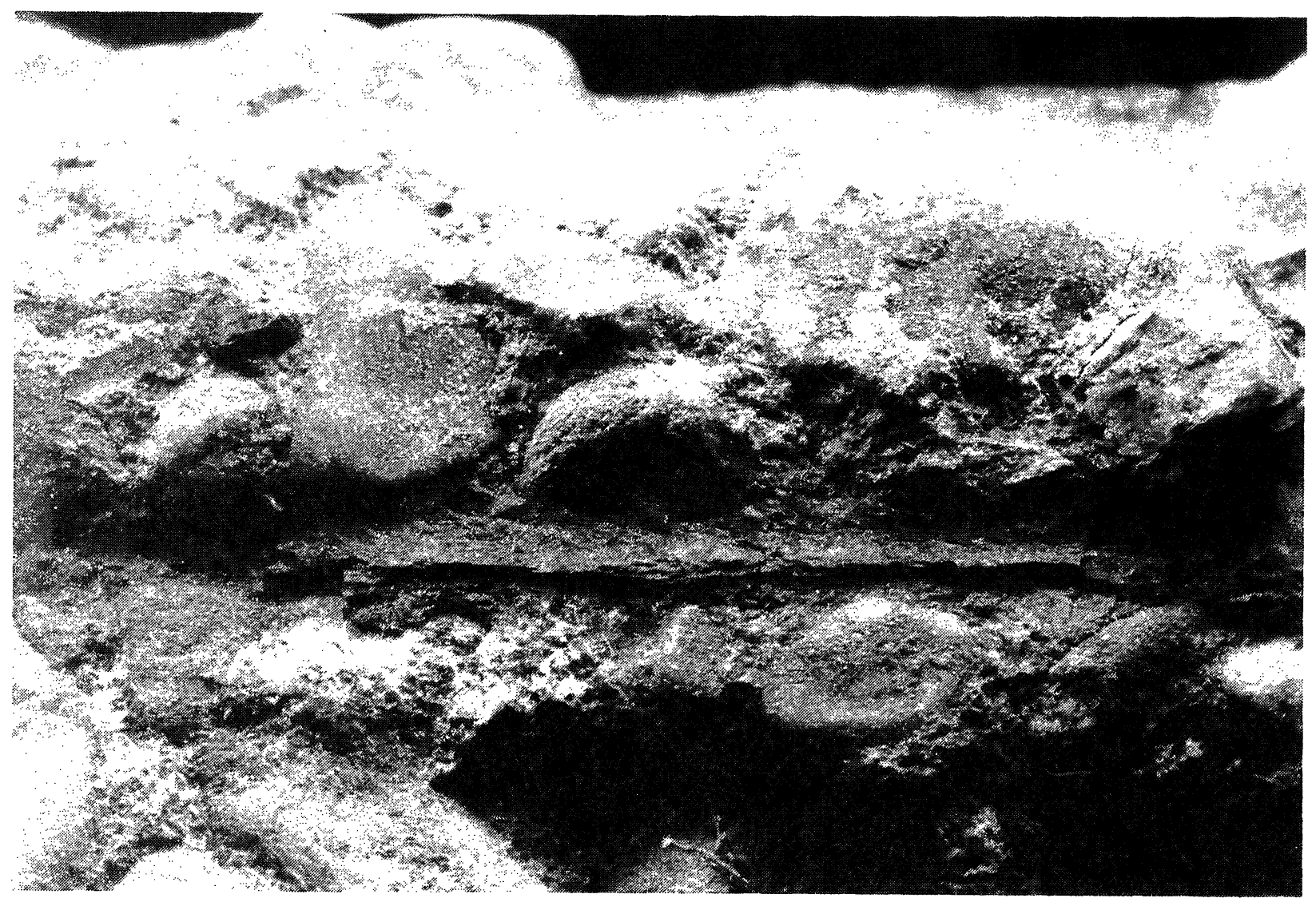

Foto 5.-Detalle del estado que presentan las armaduras. Puede observarse el óxido adherido al hormigón.

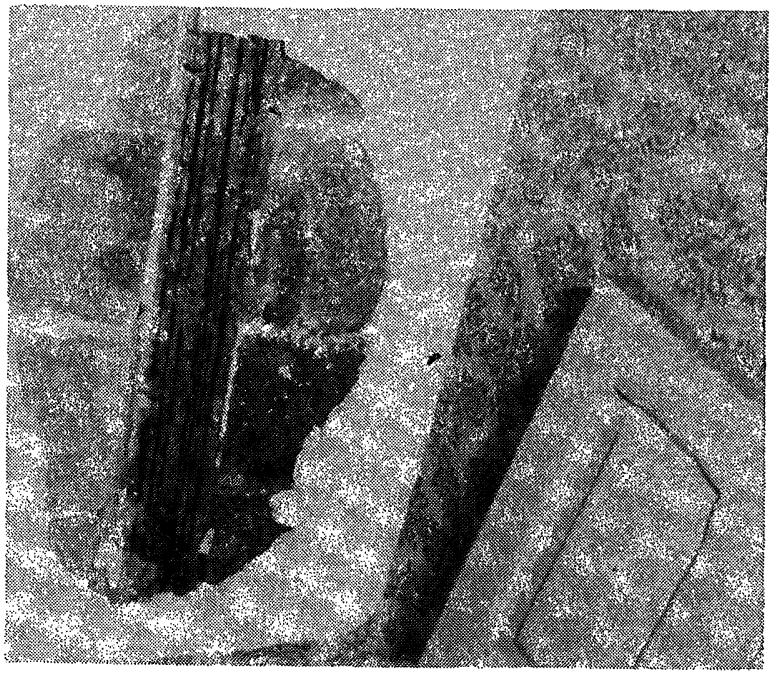

Foto 6.-Corrosión de armaduras en viguetas de forjado de cubierta. 


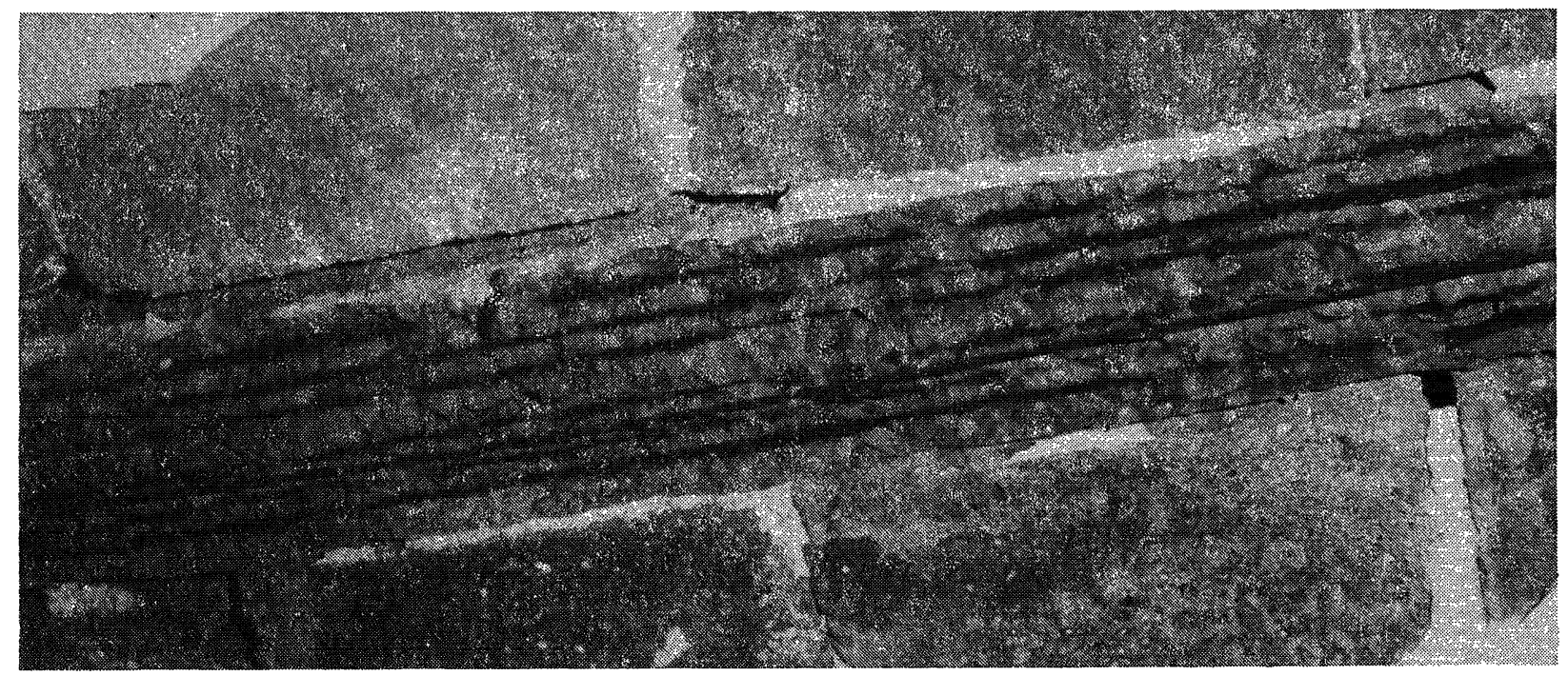

Foto 7.-Corrosión de armaduras de viguetas. Detalle ampliado de la foto 6 .

Foto 8.-Corrosión de armaduras y hormigón de viguetas descompuesto.
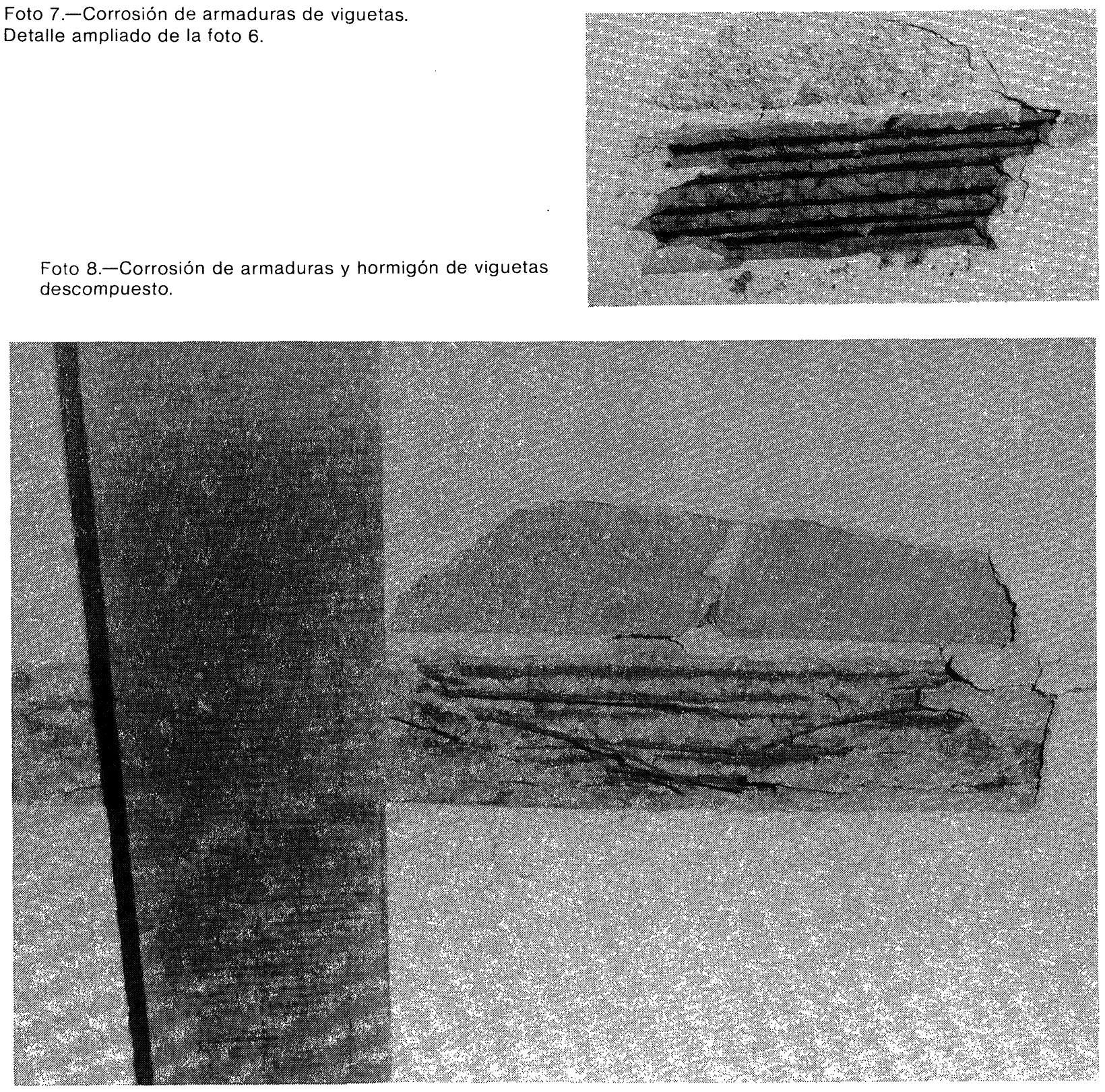

Foto 9.-Forjado apuntalado. Se observa la discontinuidad de armaduras en las viguetas. 


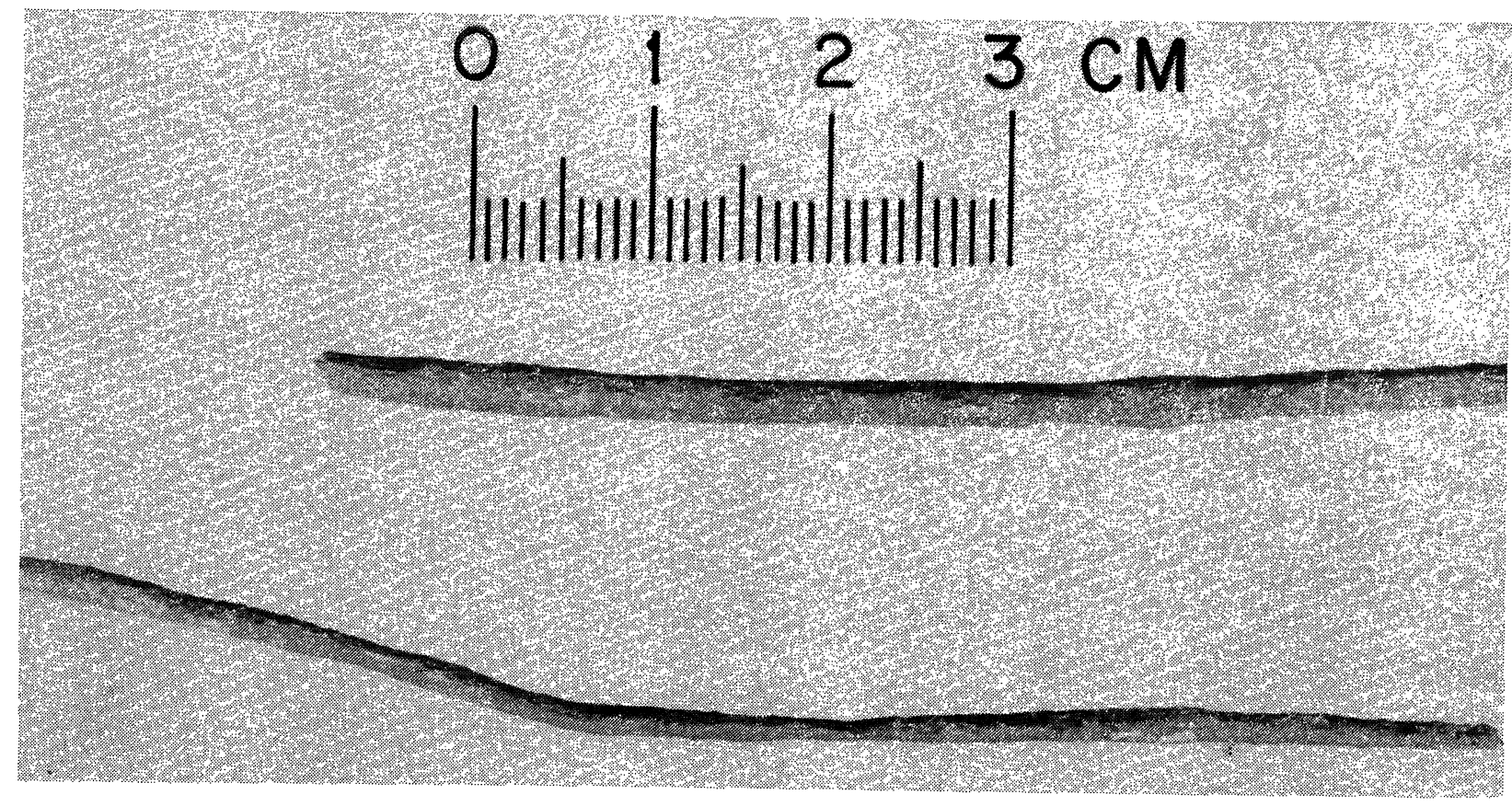
Foto 10.-Dos detalles de una misma armadura tomados en zonas diferentes. Pueden observarse las diferencias de la
sección.

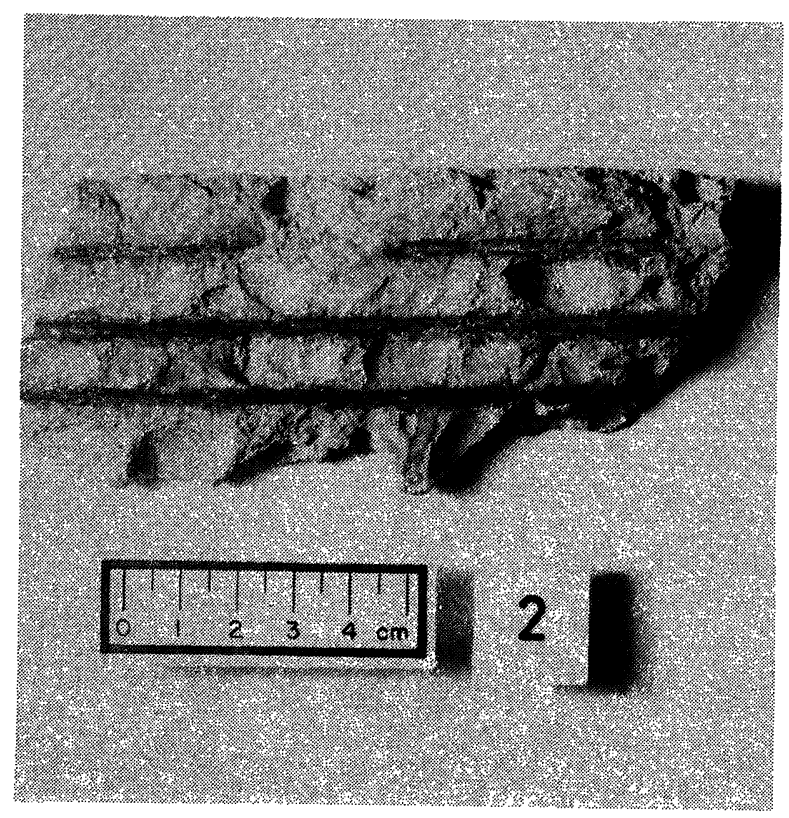

Foto 11.-Detalle de muestra del hormigón de las viguetas y de la "huella" de sus armaduras.

\section{BIBLIOGRAFIA}

T. D. ROBSON: LOS CEMENTOS ALUMINOSOS Y SUS HORMIGONES. Ed. Carcamo Hermanos, Moreira, 8, Madrid 1984. H. LAFUMA: "Los Aluminatos de calcio en el Cemento Aluminoso y en el cemento Portland". Monografia n. 239 del ICCET,
Madrid, 1964.

E. M. LEA y DESCH: QUIMICA DEL CEMENTO Y EL HORMIGON. 3. a edición. Edward Arnold Editores, Londres (1970). I. BICZOK: LA CORROSION DEL HORMIGON Y SU PROTECCION. Ediciones URMO, c/ Esparteros, 10. Bilbao 1972. 
T. VAZGUEZ, F. TRIVIÑO, A. RUIZ DE GAUNA: "Estudio de las transformaciones del cemento Aluminoso Hidratado. Influencia del Anhidrido carbónico, temperatura, Humedad y de Caliza en Polvo". Monografía n. 334 del ICCET, Madrid 1976.

J. TALABER: “High-alumina cements", VI ICCC (Moscow), Principal Paper. 1974.

J. CALLEJA: "Calculo ce Composiciones potenciales teoricamente Posibles de Cementos Aluminosos". 7 " Congréss Internat. de la Chimie du Ciments. Vol. III, pags. V-100 a V-107, París 1980.

V. LEACH: "The Determination of Alumina Cement Concrete". Concrete Durability Katherine and Bryant Mather. Intern. Conference Vol. 2. John M. Scalon Editor. ACI SP - 100-97 pp. 1903-1914, Atlanta, Georgia, USA, Abril-Mayo 1987.

H. G. MIDGLEY and J. F. RYDER: "The Relationship between Mineral Composition and Strength Development of High Alumina Cement". Cement, Concrete and Research, Vol. 7, No. pp. 669-672, Nov. 1977.

Instrucción para el proyecto y la ejecución de obras de hormigón en masa o armado, EH-88, R.D. 824/1988 de 15 de julio, BOE núm. 180, 28-07-88.

Instrucción para el proyecto y la ejecución de obras de hormigón pretensado, R.D. 1.408/77 de 18 de Febrero y R.D $1.789 / 80$ de 14 de Abril.

\section{NOTA DEL AUTOR}

Se agradece la información y colaboración técnica prestada por el Dr. Arq. D. José M. ${ }^{a}$ Jenaro para realizar el presente artículo.

\section{publicaciones del ICCET/CSIC}

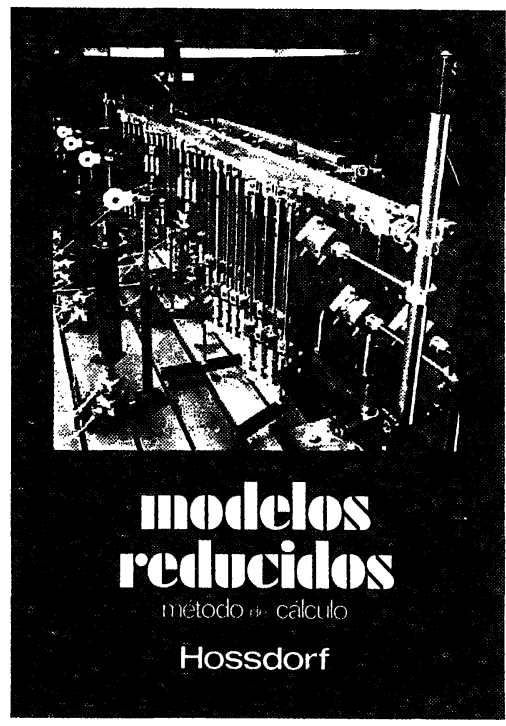

Modelos reducidos. Método de cálculo

H. Hossdorf, Ingeniero Civil

La técnica de los ensayos en modelos reducidos de estructuras sufre hoy dia una decisiva metamorfosis. Hasta hace poco era un medio más bien de artesania, que no siempre era tomado en serio por los académicos teorizant miento resistente de las estructuras complejas y a que se acudió las más de las veces, como a un último remedio debido a sus indiscutibles insuficien cias. Sin embargo, en poco tiempo y gracias a su conexión con los ordenadores digitales, se ha trans formado en un instrumento cientificamente valioso que no puede quedar a un lado en la práctica diaria del Ingeniero Proyectista.

Un volumen encuadernado en cartoné plastificado con lomo de tela, de $17 \times 24 \mathrm{~cm}$, compuesto $\mathrm{d}$ 250 páginas, 158 figuras y fotografias.

Precios: 1.800 ptas.; \$ USA 26.00

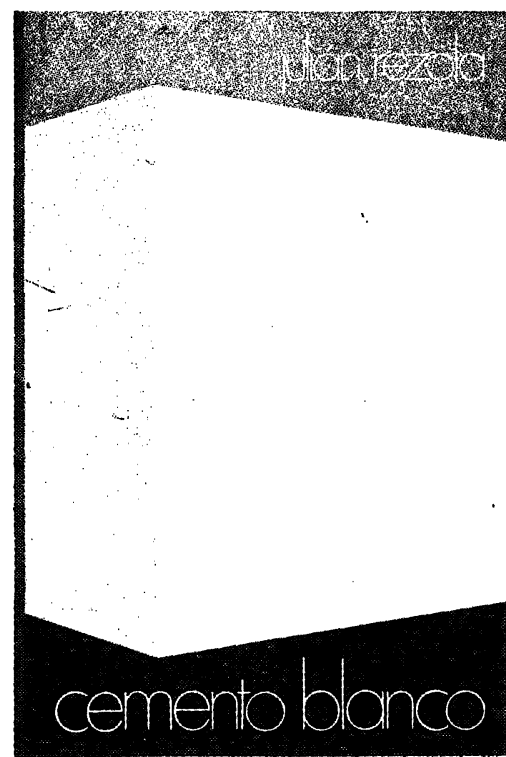

\section{Cemento blanco}

Julián Rezola

Ingeniero Quimico Dipl. I. Q S.

Sabido es que existe una extensa y documentada bibliografia sobre el cemento gris: en cambio, no puede decirse lo mismo acerca del cemento portiand blanco, ya que los escritos existentes se refieren $\tan$ sólo a algunas peculiaridades que le distinguen de aquél.

El autor nos ofrece sus profundos conocimientos y su larga experiencia tanto en laboratorio como en fabricación.

La parte descriptiva del libro se complementa con gráficos, diagramas y fotografias de gran utilidad gracos, diagramas y iogras de gran utildad, este aglomerante.

Un volumen encuadernado en cartoné policerado, de $17,4 \times 24,3 \mathrm{~cm}$, compuesto de 395 páginas, numerosas figuras, tablas y ábacos.

Precios: España, 1.700 ptas.; extranjero, $\$ 24.00$

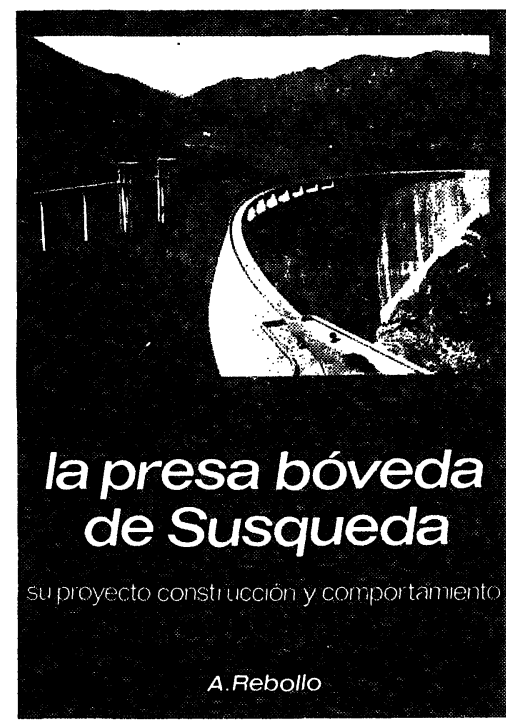

La presa bóveda de Susqueda

A. Rebollo,

Dr. Ingeniero de Caminos

El esfuerzo del constructor de presas se sitúa por su pretensión de perennidad, a contracorriente e las tendencias de la civilzación actual, caractecada por lo fungible. Pueden evocarse las 10.000 grandes.presas en funcionamiento o en construcción que enta gervicio y perennidad En a medida obras, grandes 0 pequeñas, son portadoras riesgos ecológicos $y$ a veces, catastróficos, que aumentan con el envejecimiento la gerontologia de las presas es todo un emplazo. La acción adelantada de Arturo Rebollo en este terreno marca un camino a seguir para todos los que aman su propia obra con la devoción paternal que el ha puesto en Susqueda.

Un volumen encuadernado en cartoné plastificado con lomo de tela, de $18 \times 24,5 \mathrm{~cm}$, compuesto de 408 páginas, 330 figuras y fotografias y 39 tablas. Precios: 1.700 ptas.; extranjero, \$ USA 24.00. 